\title{
Selection for Increased Spore Efficacy by Host Genetic Background in a Wheat Powdery Mildew Population
}

\author{
Lorys M. M. A. Villaréal and Christian Lannou
}

Laboratoire de Pathologie Végétale, INRA, BP 01, 78850 Thiverval Grignon, France.

Accepted for publication 21 August 2000.

\section{ABSTRACT}

Villaréal, L. M. M. A., and Lannou, C. 2000. Selection for increased spore efficacy by host genetic background in a wheat powdery mildew population. Phytopathology 90:1300-1306.

A field experiment was designed to test the hypothesis of for increased reproductive ability on different host genetic backgrounds within a wheat powdery mildew population. Studies have suggested that, in host mixtures, such selection could increase the reproduction rate of simple pathotypes that always develop on the same host genetic background, whereas complex pathotypes should not be affected because they infect different host genotypes. In our experiment, the Erysiphe graminis population reproduced for successive generations on cvs. Orkis and Etecho, either grown as pure stands or in a mixture. In an additional treatment, the host cultivar changed after each generation. Isolates were sampled in April and, after seven pathogen generations, in July. At the second sampling date and for pure stands only, mean spore efficacy was greater on the host from which isolates were sampled than on the other one. This was attributed to selection within the pathogen population for better spore efficacy on the host genetic background. This selection was independent of the virulence genes carried by the isolates. The possibility of a phenotypic plasticity effect was tested and rejected.

Additional keywords: cultivar mixture, genetic diversity, variety mixture.
Many studies have shown that cultivar mixtures are an effective method for controlling airborne parasites in crops, particularly for small grain cereals $(2,24,27)$. In a mixture of resistant and susceptible plants, the multiplication rate of a pathogen is reduced depending on the proportion of resistant plants and other factors (19). However, in the long term, cultivar mixtures might alter the genetic structure of pathogen populations by selecting pathotypes able to reproduce on most or all of the mixture components. In the literature, pathotypes able to infect two or more components in a host mixture are referred to as complex pathotypes. Theoretical $(1,9,15,18,20)$ and experimental $(6,11)$ studies have been undertaken to evaluate the genetic consequences of a mixture strategy on the evolution of pathogen populations. Their results remain partly contradictory, but it appears that complex pathotypes do not necessarily increase rapidly in frequency, as one would expect if no stabilizing selection occurred.

Leonard (17) showed that if a selective cost is associated with the virulences that are not necessary to infect a host plant, the proportions of mixture components can theoretically be chosen so as to stabilize the pathogen population at an equilibrium. Different experimental values have been measured for the cost of virulence: 14 to $39 \%$ for Puccinia graminis f. sp. avenae (17) and 4 to 6\% for $P$. graminis f. sp. tritici or Erysiphe graminis f. sp. hordei (8). However, in many other cases, virulences have no cost for the pathogen or the cost magnitude is so low that the consequences on pathogen evolution are negligible $(3,13)$.

Most of the simulation studies on pathotype competition in host mixtures are based on the concept of cost of virulence. However, it has been suggested (6) that several other factors, such as pathogen genetic background or host composition, could influence simple pathotype-complex pathotype competition in cultivar mixtures. In the current paper, we chose to focus on a selective mechanism first described by Leonard (17) with a genetically

Corresponding author: L. Villaréal; E-mail address: Lorys.Villareal@grignon.inra.fr

Publication no. P-2000-0925-03R

(C) 2000 The American Phytopathological Society diversified population of $P$. graminis, and by Chin and Wolfe (4) with a field population of E. graminis. Leonard maintained a $P$. graminis population on two different oat cultivars for seven generations and observed that the mean spore efficacy of the pathogen increased on the host on which it had reproduced but did not change on the other one. Chin and Wolfe obtained similar differentiation for complex pathotypes sampled from pure stands, but not from host mixtures where they could infect at least two components. It can be hypothesized in both cases that the observed changes were the result of selection among the different isolates present in the population of those that were best adapted to the host genetic background. Leonard (17) suggests that in a host mixture this selection for increased spore efficacy by the host genetic background could make simple pathotypes, which reproduce on the same cultivar, more competitive compared with complex pathotypes. A recent theoretical study (16) supports this hypothesis, but very few data are available to evaluate the magnitude of such selection in the field. Our objective in this study was to evaluate the potential effect of differential selection in a wheat powdery mildew population infecting a two-component host mixture. Ancillary measures were designed to test if phenotypic plasticity or avirulence genes could have interfered with our results.

\section{MATERIALS AND METHODS}

Experimental design. The experiment was conducted twice in 1997 and 1998 at the INRA Experimental Station of Versailles. Four treatments were performed in which powdery mildew populations developed successive generations either on pure stands of cv. Orkis $(\mathrm{Pm} 2+\mathrm{Pm} 8)$ or cv. Etecho $(\mathrm{Pm} 4 \mathrm{~b})$, on a random mixture of cvs. Orkis and Etecho (1:1), and in a fourth treatment, alternately on cvs. Orkis, Etecho, Orkis, and so on. The experiment was designed to obtain successive and discontinuous generations of powdery mildew (Fig. 1). For each treatment, a new set of three rows (1-m long, 20-cm wide) was planted every 2 weeks, from the end of February to the middle of July, and old plants were removed when infection had reached the next set of seedlings. Distance between rows was $10 \mathrm{~cm}$; sowing density was of $\approx 200$ seeds 
for a set of three rows. This high density allowed for better development of powdery mildew. After sowing, seeds were covered with a forcing film to ensure more regular germination and to protect the seedlings from infection during the first week after sowing. When the film was removed, the adjacent 3-week-old seedlings were already bearing sporulating lesions that started to infect the new seedlings. At this time, the oldest plants (5 weeks old) were removed. Each year, the experiment was replicated three times, at three different locations in the research station. Distance from replications was between 1 to $4 \mathrm{~km}$. This design was chosen to maximize the chance of good initial infection by natural inoculum and to limit the risk of damage to the seedlings. In 1997, one of the plots was partly damaged either by abiotic stress or by a soilborne pathogen and 10 to $20 \%$ of the plants were lost. Damage caused by birds or small animals was prevented by covering the plants with metal grids. At each location, the treatments were planted on a plot $\left(25 \times 25 \mathrm{~m}^{2}\right), 4 \mathrm{~m}$ apart from each other and separated by fallow ground. Rows were oriented perpendicularly to dominant winds. The four treatments were randomized in each plot. No fertilizer, herbicide, or fungicide was applied, and plots were hand-weeded as necessary.

Isolate sampling. The parasite population was sampled in April, shortly after the first infections were observed, and in July, after seven powdery mildew generations were obtained. Approximately 30 infected leaves per treatment subplot were collected, and a single lesion was isolated on each leaf. Isolates were cultured on detached leaf segments maintained on agar plates with $3 \%$ benzimidazole in a growth chamber at $16^{\circ} \mathrm{C}$. Each isolate was grown on two leaf segments, one of cv. Orkis and one of cv. Etecho, to separate complex isolates (virulent on both cvs. Orkis and Etecho) from simple isolates (virulent on only one of the cultivars). A relative measure of spore efficacy was performed on cvs. Orkis and Etecho for complex isolates (described below). For each treatment subplot and each date, 15 to 34 isolates were tested in 1997, except for cv. Etecho pure stand (plot 3) in April and mixture (plots 2 and 3) in April (Fig. 2, plot numebering) where the number of isolates was reduced to six after hyperparasite contamination. In 1998, 12 to 22 isolates were tested per subplot and sampling date. Isolates were maintained on leaf segments at $3^{\circ} \mathrm{C}$ for three generations in April 1997 and one generation in July 1997 and in 1998.

Measure of relative spore efficacy. Spore efficacy was measured as a fitness component of the pathogen, relative to the host genotype. Test seedlings were grown in 7-cm-wide plastic square pots. Twelve seeds were sown in a row along one of the pot edges, and seedlings were protected from airborne spores by a $20-\mathrm{cm}$-high cellophane bag. Each isolate was inoculated at the same time on two pots, one of each cultivar, in a Plexiglas settling tower $20 \mathrm{~cm}$ wide and $40 \mathrm{~cm}$ high. Before inoculation, the seedling leaves were taped on Plexiglas slides and maintained horizontally, adaxial side up. Spores were sucked from the leaf segments that the isolates were maintained on into a glass tube, projected into the settling tower, and allowed to fall for 4 min onto the seedlings. Given the large number of isolates to test, it was not possible to control the inoculum density precisely. Therefore, a relative measure of spore efficacy was performed by comparing the number of lesions on both cultivars. The average lesion density was 5.2 lesions per $\mathrm{cm}^{2}$ on the test seedlings. After inoculation, infected plants were placed in a growth chamber $\left(16^{\circ} \mathrm{C}, 14 \mathrm{~h}\right.$ of light per day) for 7 days. The number of lesions on each leaf was counted and corrected by the leaf length to obtain a mean number of lesions per square centimeter (MNL) for each isolate on each cultivar. The relative spore efficacy (RSE) was calculated as

$$
\text { RSE }=\text { MNL }(\text { Orkis }) /[\text { MNL(Orkis })+\text { MNL(Etecho })]
$$

A value of RSE close to 1 indicates high spore efficacy on cv. Orkis compared with cv. Etecho; a value close to 0 indicates high spore efficacy on cv. Etecho compared with cv. Orkis. For isolates that were not differentiated for spore efficacy, $\mathrm{RSE} \approx 0.5$.

Because RSE was measured for complex isolates only, and in an attempt to generalize our results to simple isolates, we compared the spore efficacy of simple and complex isolates on cv. Etecho, relative to susceptible cv. Barbee, according to the same method described previously. Thirty simple isolates sampled in each of the three cv. Etecho pure stands in April 1998 were compared with complex isolates sampled in the same plots. Simple isolates collected from cv. Orkis were not included in the test.

For each year and treatment, we estimated the rate of change per generation in RSE for the pathogen population. If $\overline{\operatorname{RSE}}(g)$ is the mean value for RSE at generation $(g)$, and $r$ the rate of change in RSE , then $\overline{\operatorname{RSE}}(g)=(1+r)^{g} \overline{\operatorname{RSE}}(0)$ and $r$ can be calculated as

$$
r=\left(\frac{\overline{\operatorname{RSE}}(g)}{\overline{\operatorname{RSE}}(0)}\right)^{\frac{1}{g}}-1
$$

In Chin and Wolfe's experiment (4), spore efficacy was measured on barley cvs. Hassan and Wing, after 53-day epidemics on cvs. Hassan and Wing or a mixture including cvs. Hassan and Wing. To compare them with our results, we applied equation 1 and equation 2 to Chin and Wolfe's data, assuming that (i) seven mildew generations had occurred during the epidemics and (ii) that the parasite population was not differentiated $(\overline{\mathrm{RSE}}=0.5)$ at the beginning of the epidemics.

Phenotypic plasticity. The hypothesis that phenotypic plasticity (25) could have influenced pathogen evolution was tested in a controlled condition experiment. Thirty isolates from the 1997 sampling were chosen for the test: 10 from the July sampling in cv. Etecho pure stands, with spore efficacy values lower than 0.5; 10 from the April sampling in cv. Etecho pure stands; and 10 from the July sampling in host mixtures, with RSE close to 0.5. Each isolate was duplicated and grown on detached leaf segments for eight generations on cv. Etecho (lineage E) and on cv. Orkis
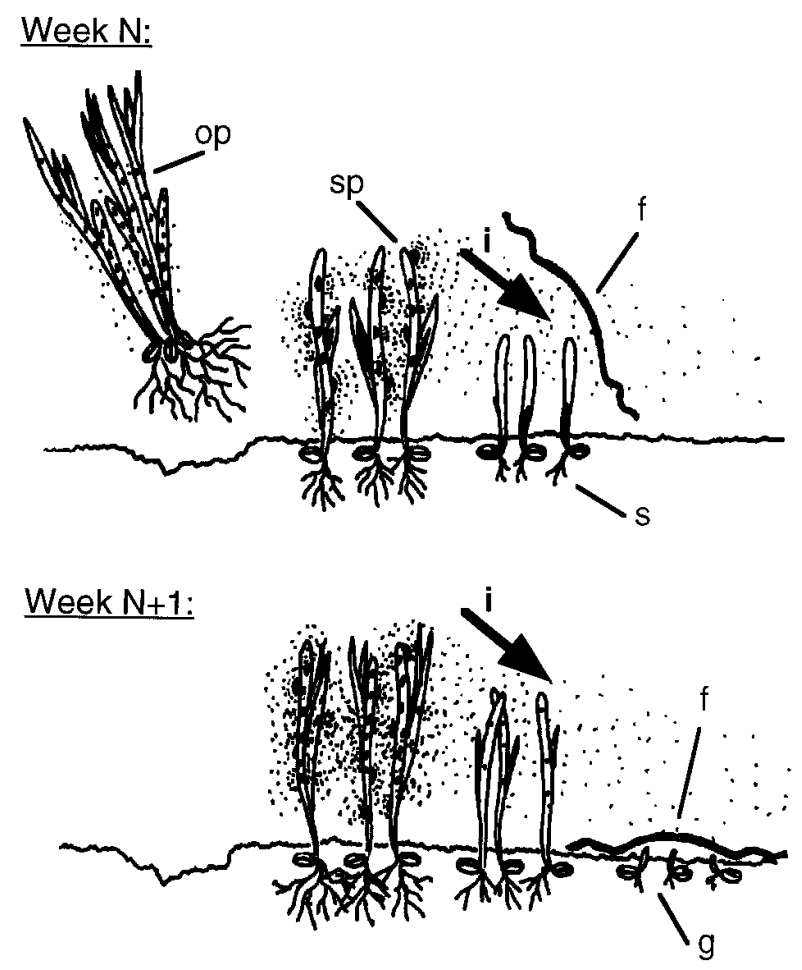

Fig. 1. Successive sowings and plant removals. Week N; 5-week-old plants (op) are removed and 1-week-old seedlings $(s)$ are exposed to infection $(i)$ by powdery mildew from sporulating 3 -week-old plants $(s p)$. The forcing film $(f)$ ensures regular germination and avoids infection before the removal of old plants. Week $\mathrm{N}+1$; new plants are sown $(g)$ and covered by the forcing film. 
(lineage $\mathrm{O}$ ). After eight generations, each isolate from lineage $\mathrm{E}$ was duplicated again to obtain two new lineages: one grown on cv. Etecho again (lineage EE) and the other grown on cv. Orkis (lineage EO), for eight generations. The same design was applied to lineage $\mathrm{O}$ to obtain two lineages (OO and $\mathrm{OE}$ ). Tests for spore efficacy were realized to compare lineages $\mathrm{E}$ and $\mathrm{O}$ after the first eight generations, and lineages $\mathrm{EE}, \mathrm{EO}, \mathrm{OO}$, and $\mathrm{OE}$ after eight further generations.

Virulence spectra. Virulence spectra were determined with a differential set of 17 wheat cultivars, including Axminster (Pm1), Ulka (Pm2), Asosan (Pm3a), Chul (Pm3b), Sonora (Pm3c), Khapli (Pm4a), Roazon (Pm4b), Hope (Pm5), TP114xStarck (Pm6), Soisson, Clement (Pm8), Aquila (Mli), Talent (Tal), Axona (resistant check), Barbee (susceptible check), Orkis (Pm2+Pm8), and Etecho (Pm4b). Pathotypes were named according to a binary code generated from the infection types (susceptible/resistant) on each differential cultivar. The virulence phenotype was determined for the complex isolates sampled in April and July 1998 in plot 5, cv. Orkis pure stand and mixture treatments, and in plot 6, all treatments (Fig. 2; plot numbering). A total of 192 isolates were tested for virulence spectra. The mean number of virulences per isolate was calculated as well as the mean number of virulences that were not necessary to infect cvs. Orkis or Etecho.
Statistical analysis. Statistical analyses were performed with the Statistical Analysis System software (SAS Institute Inc., Cary, NC). For RSE, the whole data set (1997 and 1998) was analyzed with the Mixed Procedure. A first analysis of the data showed no effect of year. We then used a mixed model including treatment and sampling date (April or July) as fixed effects and plot and interactions with plot as random effects. No data transformation was necessary according to the residual pattern. Populations in April and July were compared and effects were declared significant for an associated $P$ value lower than 0.05 . The effects of pathotype and number of virulences on RSE were tested using the general linear models (GLM) procedure. In the phenotypic plasticity essay, the final RSE values and the differences between initial and final RSE values were compared for the different lineages using the GLM procedure.

\section{RESULTS}

Selection for increased spore efficacy. For the whole data set (1997 and 1998), the pathogen spore efficacy measured on the host from which isolates were sampled increased in cvs. Orkis and Etecho pure stands, whereas it either remained constant or shifted toward a medium value (Table 1 ) in the mixture and alternate
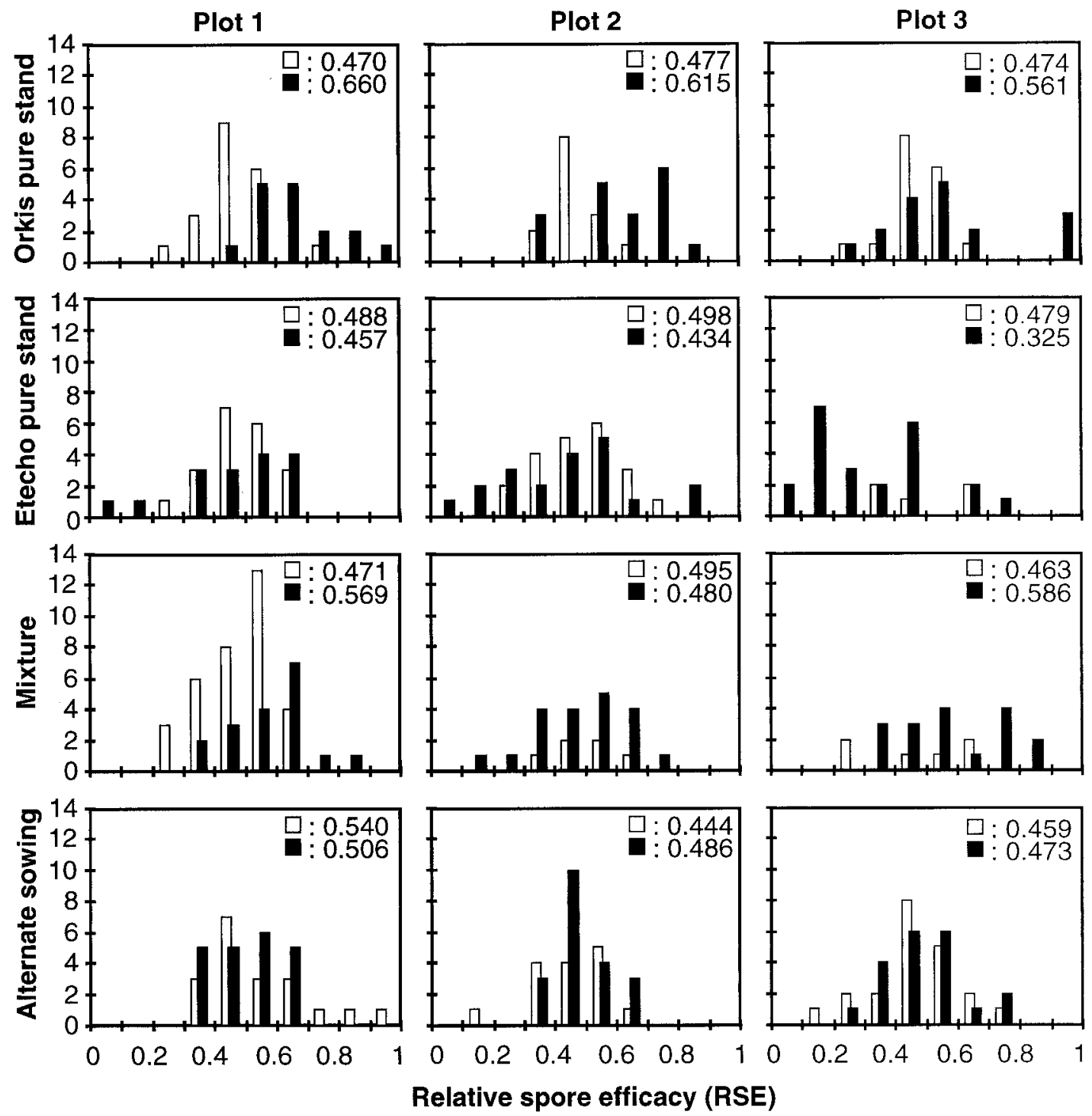

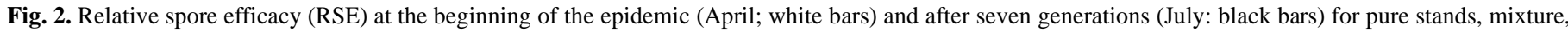

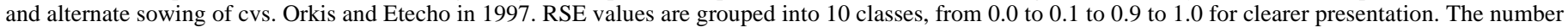
of isolates in each class is plotted against the RSE value. Mean values for RSE in April and July indicated in each graph. 
sowing treatments. RSE increased from 0.475 to 0.583 in $\mathrm{cv}$. Orkis pure stand $(P=0.0001)$, decreased from 0.496 to 0.387 in $\mathrm{cv}$. Etecho pure stand $(P=0.0001)$, and moved toward the mean value in the mixture $(0.463$ to 0.513$)$ and alternate sowing treatments $(0.475$ to 0.508$)$. There were no statistical differences between treatments in April, but three groups could be separated in

TABLE 1. Relative spore efficacy for wheat powdery mildew at the beginning of the epidemic (April) and after seven generations (July) in pure stands, mixture, and alternate sowing of cvs. Orkis and Etecho ${ }^{\mathrm{x}}$

\begin{tabular}{lrlllll}
\hline Treatment & $F$ & $P r>F$ & \multicolumn{1}{c}{ April } & July & Variation & $r^{\mathrm{z}}$ \\
\hline Orkis & 26.91 & 0.0001 & $0.475 \mathrm{ab}$ & $0.583 \mathrm{c}$ & $+22.7 \%$ & $+3.0 \%$ \\
Etecho & 25.03 & 0.0001 & $0.496 \mathrm{ab}$ & $0.387 \mathrm{~d}$ & $-22.0 \%$ & $-3.5 \%$ \\
Mixture & 5.03 & 0.0252 & $0.463 \mathrm{a}$ & $0.513 \mathrm{~b}$ & $+10.8 \%$ & $+1.5 \%$ \\
Alternate & 2.61 & 0.1068 & $0.475 \mathrm{ab}$ & $0.508 \mathrm{ab}$ & $+6.9 \%$ & $+1.0 \%$ \\
$\quad$ sowing & & & & & &
\end{tabular}

${ }^{\mathrm{x}}$ Means are calculated from the whole data set (1997 and 1998). Least square means are given for each treatment in April and July. Means followed by the same letter are not statistically different according to the Student's $t$ test $(P=0.05)$.

y Total variation between April and July.

${ }^{\mathrm{z}}$ Rate of change per generation in the relative spore efficacy, calculated from equation 2 for seven generations.
July: cv. Orkis pure stand with high values, cv. Etecho pure stand with low values, and mixture and alternate sowing with mean values.

In 1997 (Fig. 2), the RSE of isolates sampled in April was close to 0.5 , indicating no differentiation of the population for spore efficacy on the hosts. Between April and July, RSE of the pathogen population increased from 0.473 to 0.612 in $\mathrm{cv}$. Orkis pure stands. The opposite evolution was observed in cv. Etecho pure stands, where RSE decreased from 0.492 in April to 0.398 in July. In mixture and alternate sowing treatments, mean RSE values were 0.473 and 0.483 in April and 0.545 and 0.488 in July, respectively.

In 1998 (Fig. 3), RSE increased in cv. Orkis pure stands from 0.468 (April) to 0.529 (July), and decreased in cv. Etecho pure stands from 0.515 (April) to 0.405 (July). Changes differed in mixtures and alternate sowings treatments. In plots 4 and 5, the average spore efficacy remained $\approx 0.5$ between April and July, whereas in plot 6 , it increased from low values $(0.403$ in the mixture and 0.372 in the alternate sowing treatment) toward values closer to 0.5 .

The rate of change ( $r$; equation 2 ) in RSE varied between 3 and $3.5 \%$ per generation in pure stands. In the mixture and alternate sowing treatments, there was no change in 1997 and an increase
Plot 4
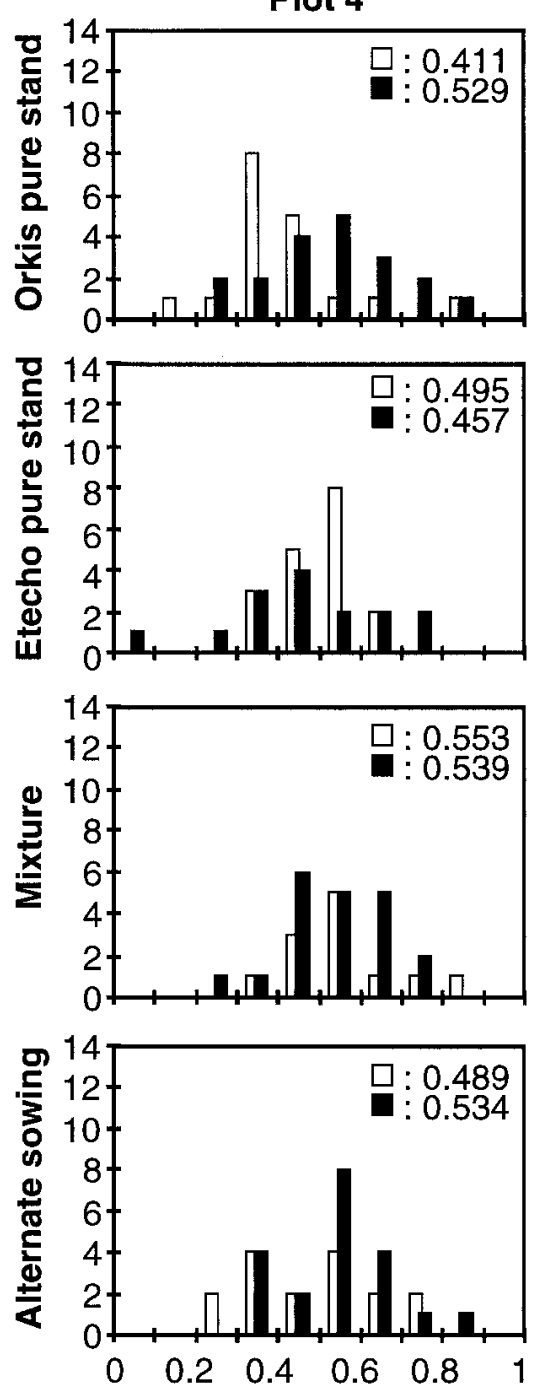

Plot 5
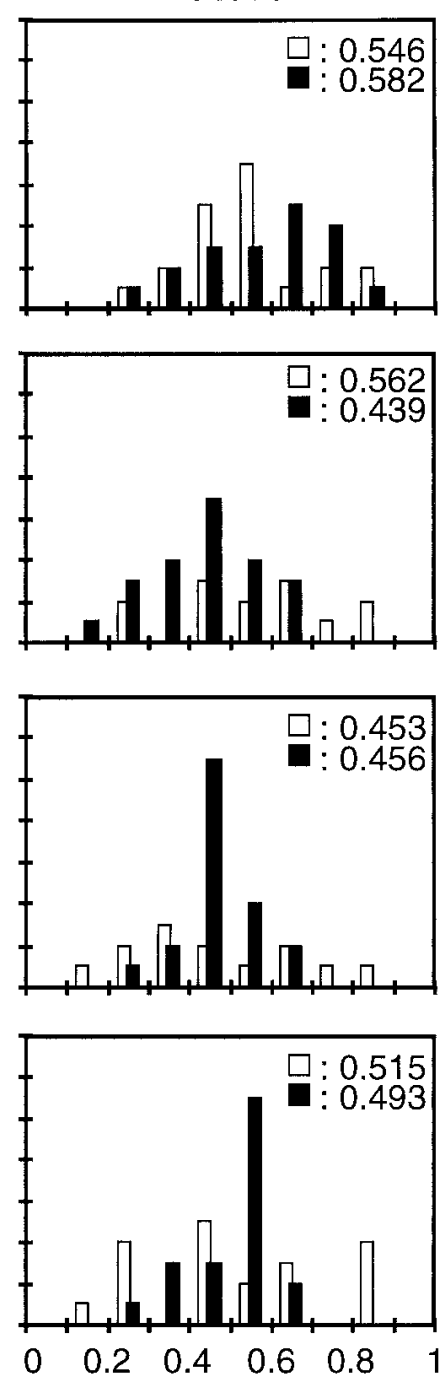

Plot 6
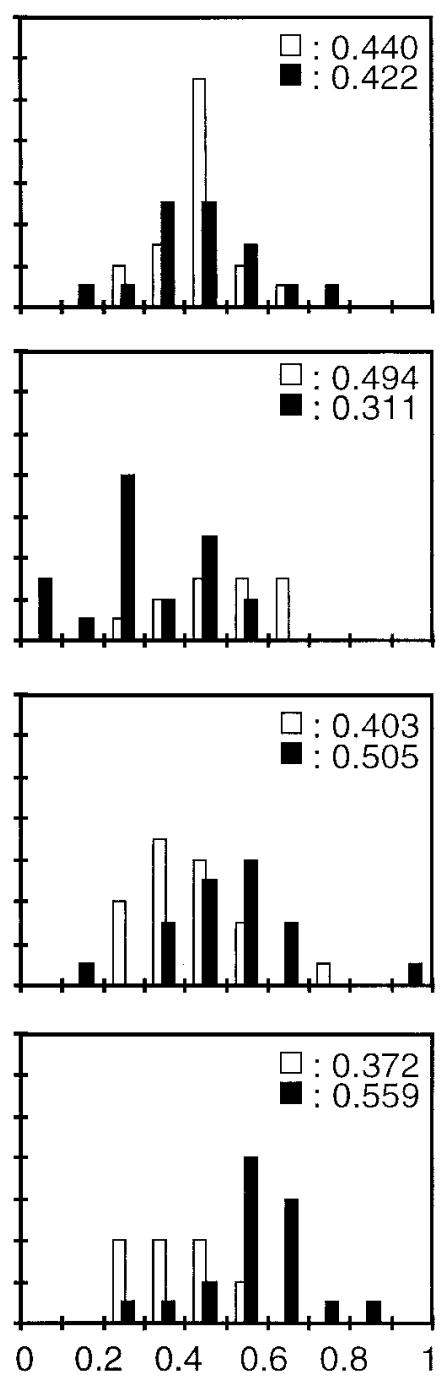

Relative spore efficacy (RSE)

Fig. 3. Relative spore efficacy (RSE) at the beginning of the epidemic (April; white bars) and after seven generations (July; black bars) for pure stands, mixture, and alternate sowing of cvs. Orkis and Etecho in 1998. RSE values are grouped in 10 classes from 0.0 to 0.1 to 0.9 to 1.0 for clearer presentation. The number of isolates in each class is plotted against the RSE value. Mean values for RSE in April and July indicated in each graph. 
of $1.7 \%$ per generation in 1998. From Chin and Wolfe's data (4), we calculated rates of change in spore efficacy close to $1.5 \%$ per generation in pure stands and $0.5 \%$ in the mixtures (Table 2).

A comparison of simple and complex isolates sampled from $\mathrm{cv}$. Etecho pure stands in April 1998 did not show any significant difference in RSE (Table 3).

Phenotypic plasticity. No change in RSE was found $(F=1.75$; $P=0.19)$ in the isolates after 8 generations on the same host for lineages $\mathrm{O}$ and $\mathrm{E}$, after 16 generations on the same host for lineages $\mathrm{OO}$ and $\mathrm{EE}$, or after 16 generations with a change in host genotype for lineages EO and OE (Table 4).

Virulence spectra. Complex pathotypes showed many virulence combinations, with at least four virulences. The population was highly diversified with 33 pathotypes in April and 34 in July (Fig. 4). Six major pathotypes were found, including 8 to 11 virulences. Among them, pathotype 7155 largely decreased in frequency between April and July and pathotype 8162 appeared only in July at a medium frequency. The main difference between these two pathotypes was that 7155 had virulences 1 and 3c, but was not virulent on cv. Clement. All other major pathotypes were found in April as well as in July at similar frequencies. No relationship appears in Figure 4 between experimental treatments and pathotype distribution. Pathotype, as well as virulence number, had no significant effect on $\operatorname{RSE}(F=1.18 ; P=0.24)$. The mean number of unnecessary virulences per pathotype was 7 .

Simple pathotype-complex pathotype competition. The sampled populations included on average $31.7 \%$ simple pathotypes in April (Table 5) with no significant difference between treatments $(P=0.28)$. In July, differences between treatments were significant $(F=12.72 ; P=0.02)$; this ratio was of $33.1 \%$ in the pure stands and $9.2 \%$ in the mixtures, and there were no more simple isolates in the alternate sowing treatments.

\section{DISCUSSION}

Experimental design. In our experiment the pathogen developed on very small plots. In such conditions, genetic drift can occur and introduce a bias in the data. However, as shown in Figure 4, the final pathogen population was highly diversified, as well as the initial population, and the main pathotypes remained present at a high frequency from the beginning to the end of the

TABLE 2. Rate of change ( $r$ in the relative spore efficacy (RSE) for barley powdery mildew in a field epidemic

\begin{tabular}{lcclllll}
\hline & \multicolumn{2}{c}{ Efficacy $^{\mathrm{w}}$} & & \multicolumn{2}{c}{ Value $^{\mathrm{x}}$} & & \\
\cline { 2 - 3 } Source $^{\mathrm{v}}$ & Hassan & Wing & & Initial & Final & Variation & $r^{\mathrm{y}}$ \\
\hline Hassan PS & 80.2 & 65.2 & & 0.500 & 0.552 & $+10.3 \%$ & $+1.4 \%$ \\
Wing PS & 55.6 & 68.8 & & 0.500 & 0.447 & $-10.6 \%$ & $-1.6 \%$ \\
Hassan (HWM) & 56.6 & 60.4 & & 0.500 & 0.484 & $-3.2 \%$ & $-0.5 \%$ \\
Wing (HWM) & 50.2 & 54.2 & & 0.500 & 0.481 & $-3.8 \%$ & $-0.6 \%$ \\
\hline
\end{tabular}

${ }^{\mathrm{v}}$ Isolates originating from cvs. Hassan or Wing either in pure stands (PS) or in mixture with cv. Midas (HWM).

${ }^{w}$ Table 6 in literature citation 4; spore efficacy in colony per spore $\left(\times 10^{-3}\right)$.

${ }^{x}$ Initial values for RSE are hypothesized. Final values for RSE are calculated from Chin and Wolfe's data with equation 1.

y Total variation between initial and final value.

${ }^{\mathrm{z}}$ Rate of change per generation in the RSE, calculated from equation 2 for seven generations.

TABLE 3. Relative spore efficacy of wheat powdery mildew against cv. Etecho compared with susceptible cv. Barbee, for simple and complex isolates sampled in cv. Etecho pure stands in April 1998

\begin{tabular}{lccc}
\hline Isolate & Plot 4 & Plot 5 & Plot 6 \\
\hline Simple & $0.410 \mathrm{a}$ & $0.434 \mathrm{a}$ & $0.389 \mathrm{a}$ \\
Complex & $0.394 \mathrm{a}$ & $0.357 \mathrm{a}$ & $0.417 \mathrm{a}$ \\
\hline
\end{tabular}

$\mathrm{z}$ Values followed by the same letter are not statistically different $(F=0.57$; $P=0.45)$. experiment, except for pathotypes 7155 and 8162 . No difference appeared in pathotype distribution between locations or sampling dates. It appears that genetic drift was of no major importance during the experiment. Exogenous inoculum and interplot exchanges could also have interfered with the observations. However, the structure of the pathogen population remained similar from April to July and no simple isolates were found in the alternate sowing treatment, where they could only have occurred by exogenous contamination. We can consider that the same population, in which selection by the host genotypes occurred, was observed at the beginning and at the end of the experiment in each treatment subplot.

The removal of old lesions probably artificially accelerated the evolution of the pathogen population and might have resulted in an overestimation of the magnitude of the selective effects. This could partly explain why the effects we measured were higher than those obtained by Chin and Wolfe (4).

Our experiment was based on the assumption that there was diversity of spore efficacy on a host genotype within the pathogen population. As suggested by Leonard (17) and Chin and Wolfe (4), differences in the aggressiveness level should result in selection during the disease season of the most aggressive pathogen genotypes, with regard to the host genotype on which the pathogen population multiplies. Aggressiveness can be considered as a measure of pathogen fitness on a host genotype and can be decomposed into several parameters, including spore efficacy, spore production rate per lesion, latent period, and lesion growth rate. Mainly for technical reasons, we chose to focus on spore efficacy as a component of pathogen fitness. It is likely, however, that similar selection also occurred for other fitness parameters in the experiment. Inoculum density was not controlled for RSE measurements. Density dependent effects on spore efficacy might have occurred for some isolates but this bias was limited, however, because the same amount of spores was deposited on cvs. Orkis and Etecho for each tested isolate. Differential interactions between isolates and cultivars have been shown for spore production $(5,12,22)$ as well as latency $(14,26)$.

Selective effects. The probability for an isolate to reproduce on the same host for several successive generations was not the same for the different treatments. In the pure stands, all the pathogen genotypes reproduced on the same cultivar for seven generations, which resulted in selection for the individuals best adapted to their host genetic background. In the alternate sowing treatment, the pathogen was allowed to grow on the same host genotype for one generation only. Hence, no selection by any of the host genetic backgrounds could occur. Data from plot 6, where RSE increased from 0.37 to 0.50 , suggests selection for nondifferentiated isolates with a similar spore efficacy on both cultivars. In the cultivar

TABLE 4. Relative spore efficacy (RSE) for 30 powdery mildew isolates after 8 and 16 generations on the same host genotype (cv. Orkis, lineages $\mathrm{O}$ and $\mathrm{OO}$; cv. Etecho, lineages $\mathrm{E}$ and $\mathrm{EE}$ ) and after 8 generations on one cultivar and 8 further generations on the other cultivar (lineages $\mathrm{OE}$ and $\mathrm{EO}$ )

\begin{tabular}{|c|c|c|c|c|c|}
\hline \multirow[b]{2}{*}{ Isolates (1997) } & \multirow[b]{2}{*}{$\mathrm{RSE}^{\mathrm{z}}$} & \multicolumn{2}{|c|}{ After 8 generations } & \multicolumn{2}{|c|}{ After 16 generations } \\
\hline & & Lineage & RSE & Lineage & RSE \\
\hline \multirow[t]{4}{*}{ Etecho, April } & \multirow[t]{4}{*}{0.505} & \multirow[t]{2}{*}{$\mathrm{O}$} & \multirow[t]{2}{*}{0.493} & $\mathrm{OO}$ & 0.507 \\
\hline & & & & $\mathrm{OE}$ & 0.501 \\
\hline & & \multirow[t]{2}{*}{$\mathrm{E}$} & \multirow[t]{2}{*}{0.502} & EO & 0.492 \\
\hline & & & & $\mathrm{EE}$ & 0.515 \\
\hline \multirow[t]{4}{*}{ Etecho, July } & \multirow[t]{4}{*}{0.435} & \multirow[t]{2}{*}{$\mathrm{O}$} & \multirow[t]{2}{*}{0.432} & $\mathrm{OO}$ & 0.440 \\
\hline & & & & $\mathrm{OE}$ & 0.442 \\
\hline & & \multirow[t]{2}{*}{$\mathrm{E}$} & \multirow[t]{2}{*}{0.456} & EO & 0.430 \\
\hline & & & & $\mathrm{EE}$ & 0.433 \\
\hline \multirow{4}{*}{ Mixture, July } & \multirow{4}{*}{0.510} & \multirow[t]{2}{*}{$\mathrm{O}$} & \multirow[t]{2}{*}{0.482} & $\mathrm{OO}$ & 0.480 \\
\hline & & & & $\mathrm{OE}$ & 0.493 \\
\hline & & \multirow[t]{2}{*}{$\mathrm{E}$} & \multirow[t]{2}{*}{0.485} & EO & 0.491 \\
\hline & & & & $\mathrm{EE}$ & 0.485 \\
\hline
\end{tabular}

${ }^{\mathrm{z}}$ Mean RSE value at the beginning of the experiment. 
mixture, the probability for a spore released from one of the cultivars to produce an infection on the same host genotype was theoretically 0.5 , the frequency of that cultivar in the new set of seedlings. Even though local heterogeneity in cultivar distribution could have resulted in temporary drifts in the mean spore efficacy value, no significant change was found in spore efficacy for the pathogen population that developed in the cultivar mixture.

We measured spore efficacy as a relative value, and as a consequence, for complex isolates only. We can assume that similar selection occurred among simple isolates in the host mixtures as among complex isolates in the pure stands because, in host mixtures, simple isolates always reproduce on the same host. No differences were found in mean spore efficacy on cv. Etecho compared with cv. Barbee for simple and complex isolates, which suggests that spore efficacy was not related to the complexity level of the isolates. A difference between simple and complex isolates could have been introduced by costs for unnecessary virulences. It is unlikely, however, that costs of virulence interfered with selection for spore efficacy in our experiment. First, the terms simple and complex are used here with regard to the resistance genes present in cvs. Orkis and Etecho only. The actual number of virulences per isolate could be as high as 12 (Fig. 4). Second, no statistical relationship was found in our data between spore efficacy value and number of virulences in the isolates. Particularly, there was no difference in the mean spore efficacy value for the six major pathotypes. We can consider that selection for spore efficacy by the host genotype was independent of the virulence genes in our experiment.
Phenotypic plasticity can result in changes in the phenotype depending on the conditions in which the organism develops (25). The hypothesis of plasticity in spore efficacy on different host genetic backgrounds was rejected by a controlled condition experiment. It can be concluded from our field data that the observed changes in RSE were the consequences of selection among different genotypes.

Selection for increased spore efficacy by host genotype. Our results suggest that this selection by the host genetic background is a selective force, independent of cost of virulence, that participates in stabilizing selection for pathogen populations developing in host mixtures. Two conditions are required for this selection to be effective: genetic heterogeneity of the host population, which is realized in cultivar mixtures, and genetic diversity in the pathogen

TABLE 5. Percentage of simple pathotypes for wheat powdery mildew at the beginning of the epidemic (April) and after seven generations (July) in pure stands, mixture, and alternate sowing of cvs. Orkis and Etecho in $1998^{z}$

\begin{tabular}{lccccccc}
\hline & Plot 4 & & \multicolumn{2}{c}{ Plot 5 } & & \multicolumn{2}{c}{ Plot 6 } \\
\cline { 2 - 2 } \cline { 7 - 8 } \cline { 7 - 8 } Source & April & & April & July & & April & July \\
\hline Orkis & 36.7 & & 26.7 & 43.3 & & 30.0 & 28.2 \\
Etecho & 30.0 & & 46.7 & 36.6 & & 43.0 & 28.0 \\
Mixture & 33.3 & & 26.7 & 13.9 & & 10.0 & 5.0 \\
Alternate sowing & 40.0 & & 36.7 & 0.0 & & 20.0 & 0.0 \\
Mean value & 35.0 & & 34.2 & - & & 25.8 & - \\
\hline
\end{tabular}

${ }^{\mathrm{z}}$ Data from plot 4 for July are missing. Differences between treatments were significant in July $(P=0.02)$ and not significant in April $(P=0.28)$.

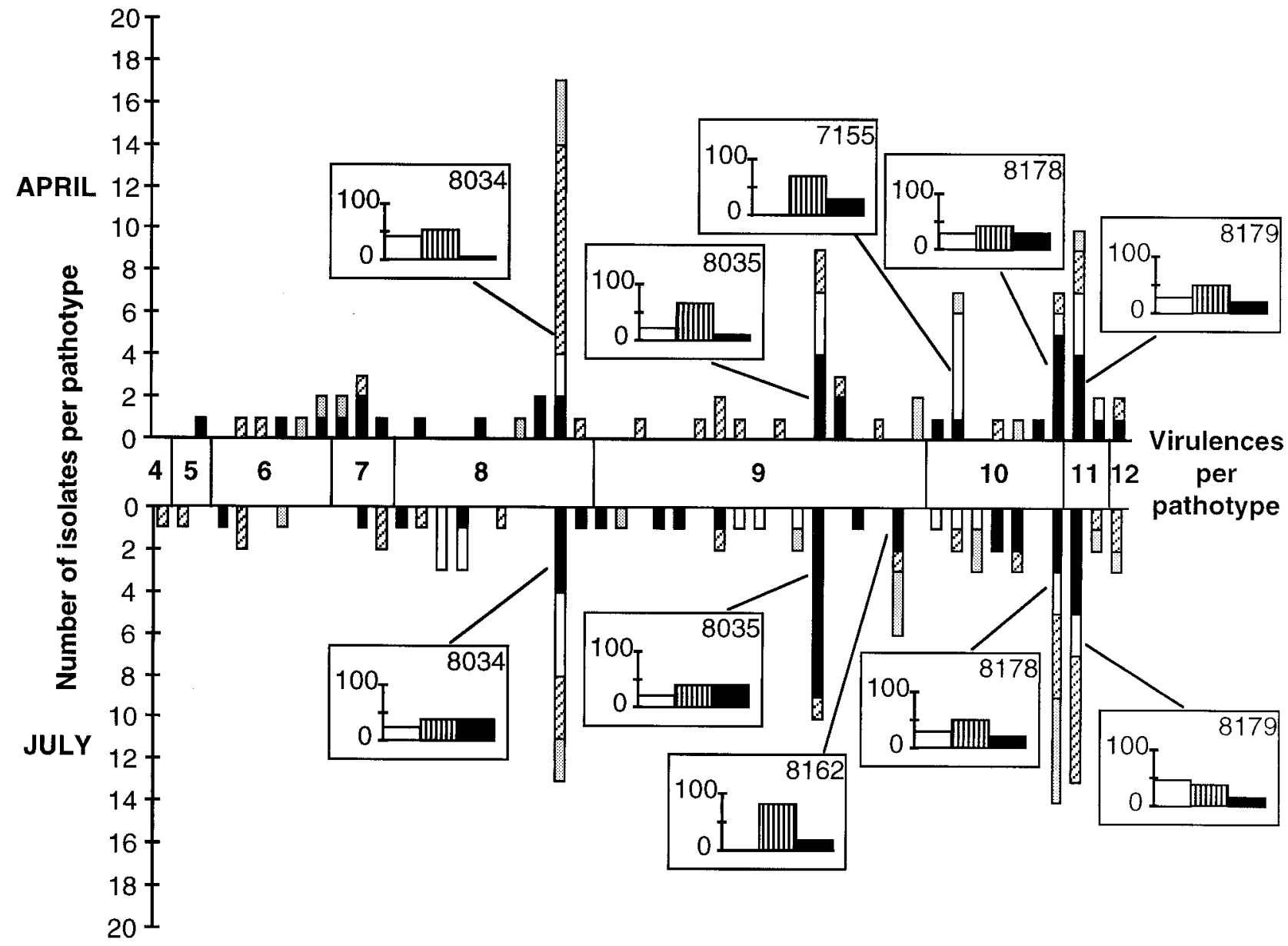

Fig. 4. Pathotype distribution in the sampled populations at the beginning of the epidemic (April) and after seven generations (July) in 1998. Virulence spectra were identified on a 17-cultivar differential set. Abscissa are the number of virulences and ordinates are the number of isolates for each pathotype. Symbols in the bars indicate the treatment from which isolates were sampled: black $=\mathrm{cv}$. Orkis pure stand (plots 5 and 6$)$, white $=\mathrm{cv}$. Etecho pure stand $($ plot 6 ), lines $=$ mixture (plots 5 and 6), and shaded = alternate sowing (plot 6). For each major pathotype, inserts show the population structure for relative spore efficacy (RSE) in April and July, divided into three classes: RSE $<0.4$ (white), RSE $>0.6$ (black), and $0.4<$ RSE $<0.6$ (lines). Pathotype number indicated in the upper right corner. 
population. With some exceptions (10), most pathogen populations appear to be genetically diversified, as shown with various physiological or molecular markers. Diversity has been demonstrated even for pathogens exhibiting a limited number of pathotypes like Venturia inaequalis in New Zealand (21). It is not known, however, whether these pathogens exhibit intrapathotype diversity in aggressiveness with regard to the host genotype. Available data usually describe differential interactions between a limited number of isolates and cultivars. For instance, Flier et al. (7) described differential variation in aggressiveness for 39 isolates of Phytophthora infestans when tested on five potato cultivars, that is independent of the host resistance genes, and Clifford and Clothier (5) show differential interactions between Puccinia hordei isolates and four different barley cultivars. Other differential interactions between isolates and cultivars were found for Septoria tritici and wheat (28), Rhizoctonia solani and tulip, sugar beet and potato cultivars (23), E. graminis and wheat (22), and Puccinia recondita and wheat (26). On the other hand, for pathogens that develop clonal populations, differential selection by the host genetic background probably does not occur at the field level.

In our experiment, the frequency of simple pathotypes in the pure stands was $35.6 \%$ in April and $33.1 \%$ in July. In the mixtures, the simple pathotype frequency was $23.3 \%$ in April and $9.2 \%$ in July. Considering that half of the simple pathotype spores were lost on resistant plants for each generation in the host mixtures, the expected frequency for simple pathotypes can be calculated after seven generations. Leonard (17) proposes an equation to calculate the relative frequency of two parasite genotypes for successive generations. According to his model, considering a multiplication rate for simple pathotypes half that for complex pathotypes (i.e., an alloinfection rate of 1.0) and starting from simple pathotype frequencies of 23.3 or $35.6 \%$, one would expect a final frequency lower than $0.5 \%$ for the simple pathotypes after seven generations. The observed final frequency $(9.2 \%)$ for simple pathotypes in the experiment was then greater than the expected frequency, according to Leonard's model. This could be interpreted as a consequence of selection for increased spore efficacy that contributed to reducing the increase in frequency of complex isolates in the mixtures.

\section{LITERATURE CITED}

1. Barrett, J. A. 1980. Pathogen evolution in multilines and variety mixtures. Z. Pflanzenkr. Pflanzenschutz. 87:383-396.

2. Borlaug, N. E. 1953. New approach to the breeding of wheat varieties resistant to Puccinia graminis tritici. (Abstr.) Phytopathology 43(suppl.): S467.

3. Bronson, C. R., and Ellingboe, A. H. 1986. The influence of four unnecessary genes for virulence on the fitness of Erysiphe graminis f. sp. tritici. Phytopathology 76:154-158.

4. Chin, K. M., and Wolfe, M. S. 1984. Selection of Erysiphe graminis in pure and mixed stands of barley. Plant Pathol. 33:535-546.

5. Clifford, B. C., and Clothier, R. B. 1974. Physiologic specialization of Puccinia hordei on barley hosts with non-hypersensitive resistance. Trans. Br. Mycol. Soc. 63:421-430.

6. Dileone, J. A., and Mundt, C. C. 1994. Effect of wheat cultivar mixtures on populations of Puccinia striiformis races. Plant Pathol. 43:917-930.

7. Flier, W. G., Turkensteen, L. J., Mulder, A., and Van den Bosch, G. B.
M. 1998. Variation in aggressiveness to potato tubers in local populations of Phytophthora infestans in the Netherlands. Proc. Int. Congr. Plant Pathol., 7th.

8. Grant, M. W., and Archer, S. A. 1983. Calculation of selection coefficients against unnecessary genes for virulence from field data. Phytopathology 73:547-551.

9. Groth, J. V. 1976. Multilines and "super-races": A simple model. Phytopathology 66:937-939.

10. Hovmøller, M. S., Ridout, C. J., and Brown, J. K. M. 1998. Molecular variation in wheat yellow rust in Northern Europe. Proc. Int. Congr. Plant Pathol., 7th.

11. Huang, R., Kranz, J., and Welz, H. G. 1994. Selection of pathotypes of Erysiphe graminis f. sp. hordei in pure and mixed stands of spring barley. Plant Pathol. 43:458-470.

12. Johnson, R., and Taylor, A. J. 1972. Isolates of Puccinia striiformis collected in England from the wheat varieties Maris Beacon and Joss Cambier. Nature 238:105-106.

13. Kolmer, J. A. 1993. Selection in a heterogeneous population of Puccinia recondita f. sp. tritici. Phytopathology 83:909-914.

14. Kuhn, R. C., Ohm, H. W., and Shaner, G. E. 1978. Slow leaf-rusting resistance in wheat against twenty two isolates of Puccinia recondita. Phytopathology 68:651-656.

15. Lannou, C., and Mundt, C. C. 1996. Evolution of a pathogen population in host mixtures: Simple race-complex race competition. Plant Pathol. 45:440-453.

16. Lannou, C., and Mundt, C. C. 1997. Evolution of a pathogen population in host mixtures: Rate of emergence of complex races. Theor. Appl. Genet. 94:991-999.

17. Leonard, K. J. 1969. Selection in heterogeneous populations of Puccinia graminis f. sp. avenae. Phytopathology 59:1851-1857.

18. Marshall, D. R. 1989. Modeling the effects of multiline varieties on the population genetics of plant pathogens. Pages 284-317 in: Plant Disease Epidemiology II. Genetics, Resistance, and Management. Vol. 2. K. J. Leonard and W. E. Fry, eds. McGraw-Hill Publishing Co., New York.

19. Mundt, C. C. 1989. Modeling disease increase in host mixtures. Pages 150-181 in: Plant Disease Epidemiology II. Genetics, Resistance, and Management. Vol. 2. K. J. Leonard and W. E. Fry, eds. McGraw-Hill Publishing Co., New York.

20. Ostergård, H. 1983. Predicting development of epidemics on cultivar mixtures. Phytopathology 73:166-172.

21. Patterson, J., Plummer, K. M., Bowen, J. K., and Newcomb, R. D. 1998. Molecular analysis of the New Zealand population of Venturia inaequalis. Proc. Int. Congr. Plant Pathol., 7th.

22. Rouse, D. I., Nelson, R. R., MacKenzie, D. R., and Armitage, C. R. 1980. Components of rate-reducing resistance in seedlings of four wheat cultivars and parasitic fitness in six isolates of Erysiphe graminis f. sp. tritici. Phytopathology 70:1097-1100.

23. Schneider, J. H. M., Van den Boogert, P. H. J. F., and Heijbroek, W. 1998. Exploring differential interactions between Rhizoctonia solani isolates and host genotypes in three pathosystems. Proc. Int. Congr. Plant Pathol., 7th.

24. Smithson, J. B., and Lenné, J. M. 1996. Varietal mixtures: A viable strategy for sustainable productivity in subsistence agriculture. Ann. Appl. Biol. 128: 127-158.

25. Sultan, S. E. 1995. Phenotypic plasticity and plant adaptation. Acta Bot. Neerl. 44:363-383.

26. Todorova, M. 1994. Latency period of Puccinia recondita f. sp. tritici on cultivars with different type of resistance. Cereal Rusts Powdery Mildew Bull. 22:22-26.

27. Wolfe, M. S. 1985. The current status and prospects of multiline cultivars and variety mixtures for disease resistance. Annu. Rev. Phytopathol. 23:251-273.

28. Zhan, J., Mundt, C. C., and McDonald, B. A. 1998. Measuring immigration and sexual reproduction in field populations of Mycosphaerella graminicola. Phytopathology 88:1330-1337. 